\title{
Temporal study of estrogenic responses of mussel (Mytilus galloprovinciallis) extracts applied to reporter cell lines
}

\author{
Arthur David $^{a}$, Sonia Dagnino ${ }^{a, b}$, Yves Pichot $^{c}$, Dominique Munaron $^{c}$, Aurélie Escande $^{a, b}$, \\ Claude Casellas $^{a}$, Hélène Fenet ${ }^{a}$ and Elena Gomez ${ }^{a}{ }^{*}$
}

\footnotetext{
a Hydrosciences, UMR 5559-Faculté de Pharmacie Avenue Charles Flahaut, F-34093 Montpellier Cedex 5, BP 14491, France

b INSERM, Signalisation Hormonale, Environnement et Cancer, Centre de Recherche en Cancérologie de Montpellier, Parc Euromédecine - CRLC Val d'Aurelle, F-34298 Montpellier Cedex 5, France

${ }^{c}$ IFREMER, Station de Sète, 34200 Sète, France
}

*: Corresponding author: Elena Gomez, Tel.: +33 4675481 24; fax: +33 4675486 95, email address : egomez@univ-montp2.fr

\begin{abstract}
:
In vitro bioassays would facilitate monitoring of estrogen-like compounds in mussels (Mytilus galloprovincialis) since they tend to accumulate lipophilic compounds in their fat and muscle tissue. However, estradiol (E2) steroid (already identified in mussels) could induce false positive responses. This study focuses on temporal variability in estrogenic responses of mussel extracts and the possible relation of this response with E2 levels. The reproductive cycle and growth were thus monitored for six months in sexed mussels. E2 levels were similar between genders and these levels varied with reproductive stages. human estrogen receptor (hER) activities were similar at all stages except in February. E2 present in male and female extracts accounted for part of the hER activation observed, but no correlation was found between E2 levels and hER activities.
\end{abstract}

Keywords: Biomonitoring; Estradiol; Mytilus galloprovinciallis; Reporter cell lines; ELISA 


\section{Introduction}

Sensitive methods are required to detect trace residues of environmental estrogen contaminants in aquatic systems. Several studies have demonstrated the efficacy of in vitro recombinant receptor reporter gene bioassays for the detection of chemicals with estrogenic activities (Balaguer et al., 1999; Fenet et al., 2003). Mussels tend to accumulate lipophilic compounds in their fat and muscle tissue. Mussel extracts could thus be applied on reporter cell lines to monitor xenoestrogen exposure in aquatic systems. Bayen et al. (2004) screened androgenic and estrogenic activities in mussel (Perna viridis) extracts. The authors found a significant correlation between androgenic activities, in the presence of dihydrotestosterone, and persistent organic pollutants, but noted that it was difficult to clearly interpret the estrogen-like activities of mussel extracts screened with ER- $\alpha$ and ER- $\beta$. The authors suggested that naturally occurring estrogens could induce false positive responses. Vertebrate-type steroids like E2 have already been identified in mussels (Reis-Henriques et al., 1990). It has not yet been confirmed that E2 has an impact on reproduction in molluscs, but variations in E2 levels in mussels could alter estrogenic responses in bioassays. The aim of this study was thus to study temporal variability in estrogen responses and to evaluate the relation of this response with E2 levels in mussels. We therefore focused on the influence of gender and biological cycle (growth and reproduction) in Mytilus galloprovinciallis, and a 6-month follow up was carried out with hER reporter cell line bioassays and E2 analysis (ELISA).

\section{Methods}

Mediterranean mussels (Mytilus galloprovinciallis) of homogenous size were transplanted at an experimental site in Thau lagoon (Sète, France). 150 mussels were collected and sexed on a monthly basis from February to July. E2 analysis and reporter cell line bioassays were carried out on a randomly sampled pool of 10 males and 10 females, and a histological study was conducted on another pool of 10 males and 10 females. For this latter study, the soft body was fixed in Davidson's fixative, dehydrated through increasing alcohol concentrations, embedded in paraffin, sectioned (5 $\mu \mathrm{m})$ and stained with Prenant Gabe's hematoxylin, and eosin. Five maturation stages were determined on the basis of the criteria of Echtian et al. (2004). A condition index (Cl) ratio (dry flesh/shell weight) was determined in 10 males and 10 females. Microwave-assisted extractions were performed on mussel tissues with a $30 \mathrm{~mL}$ acetone/n-hexane mixture (1:1, v:v). Stably transfected luciferase reporter cell lines (MELN), as described in Pillon et al. (2005), were used for hER- $\alpha$ activation studies. The results are expressed as a percentage of luciferase transactivation per well for a dilution of mussel extract and were measured in quadruplicate. E2 levels were determined in mussels using commercial ELISA kits (Spibio, Montigny le Bretonneux, France) and samples were tested in triplicate at two different dilutions at least. Extracts for bioassays were treated with $1 \mathrm{ml}$ of sulphuric acid (5\%) and then purified, like extracts for the E2 analysis, following a two step clean-up procedure using solid-phase extraction with cartridges of $500 \mathrm{mg}$ florisil.

Means of $\mathrm{Cl}$ were compared using a one-way analysis of variance (ANOVA). Assumption tests of normality and equal variance were performed before ANOVA. Multiple range tests pinpointed which month was different when significant differences between $\mathrm{Cl}$ means were detected via ANOVA. $\mathrm{Cl}$ of males and females were compared with a Student t-test for a normal distribution. Significance was set at $p<0.05$ in all cases.

\section{Results and Discussion}

The histological study (Fig. 1) showed that most of the selected mussels were ripe during the winter (February) and the spawning season extended throughout the spring (March to May). A short rest period was observed in May, with an indifferent stage period in June and July. There was a decrease in $\mathrm{Cl}$ (Table 1) between February and April, which could be explained by the fact that energy was used for gamete development. The lowest $\mathrm{Cl}$ value corresponded to gamete emission. No differences were observed between genders regarding E2 levels. The lowest E2 levels in mussel extracts were noted in February and March, which corresponds to the development and maturity period. These E2 levels increased in males and females in April and May, corresponding to the mussel spawning stage. The E2 results were in accordance with those of Kaloyianni et al. (2005), who observed an annual variation 
in E2 levels in unsexed extracts of Mytilus galloprovincialis, and with the results of Gauthier-Clerc (2006) who found similar E2 profiles between Mya arenaria (mollusc bivalves) males and females. hER activities were similar at all stages except in February, during the development and maturity stage. E2 present in male and female extracts accounted for part of the observed hER activation, but there was no correlation between E2 levels and hER activities.

In conclusion, the gender of mussels is not a problem for xenoestrogen biomonitoring; temporal variations in hER activities were not correlated with E2 levels during this 6-month study. Complementary studies involving mussel exposure to xenoestrogen in controlled conditions could reveal whether the discrepancies between hER activation and E2 levels were due to xenoestrogens.

\section{Acknowledgements}

This work was funded by PNRPE (French endocrine disrupter research programme). Michel Mathieu and François Galgani are gratefully acknowledged for their helpful discussions.

\section{References}

Bayen, S., Gong, Y., Chin, H. S., Lee, H. K., Leong, Y. E., \& Obbard, J.P. (2004). Environmental Health Perspective, 112, 1467-1471.

Balaguer, P., François, F., Comunale, F., Fenet, H., Boussioux, A.-M., Pons, M., Nicolas, J.-C., \& Casellas, C. (1999). Science of the Total Environment, 233, 47-56.

Etchian, O.A., Pellerin, J., Audet, C. \& Mathieu, M. (2004). Comparative Biochemistry and Physiology - Part B: Biochemistry \& Molecular Biology, 139, 287-97.

Fenet, H., Gomez, E., Pillon, A., Rosain, D., Nicolas, J.-C., Casellas, C., \& Balaguer, P. (2003). Archives of Environmental Contamination and Toxicology, 44, 1-6.

Gauthier-Clerc, S., Pellerin, J., \& Amiard, J.C. (2006). General and Comparative Endocrinology, 145, 133-139.

Kaloyianni, M., Stamatiou, R., \& Dailianis, S. (2005). Comparative Biochemistry and Physiology Part C: Toxicology \& Pharmacology, 141, 257-266.

Pillon, A., Boussioux, A.-M., Escande, A., Aït-Aïssa, S., Gomez, E., Fenet, H., Ruff, M., Moras, D., Vignon, F., Duchesne, M.-J., Casellas, C., Nicolas, J.-C., \& Balaguer, P. (2005). Environmental Health Perspectives, 113(3), 278-284.

Reis-Henriques, M.A., Le Guellec, D., Remy-Martin, J.P., \& Adessi, G.L. (1990).Comparative Biochemistry and Physiology Part B: Biochemistry and Molecular Biology 95, 303-309. 
Figures

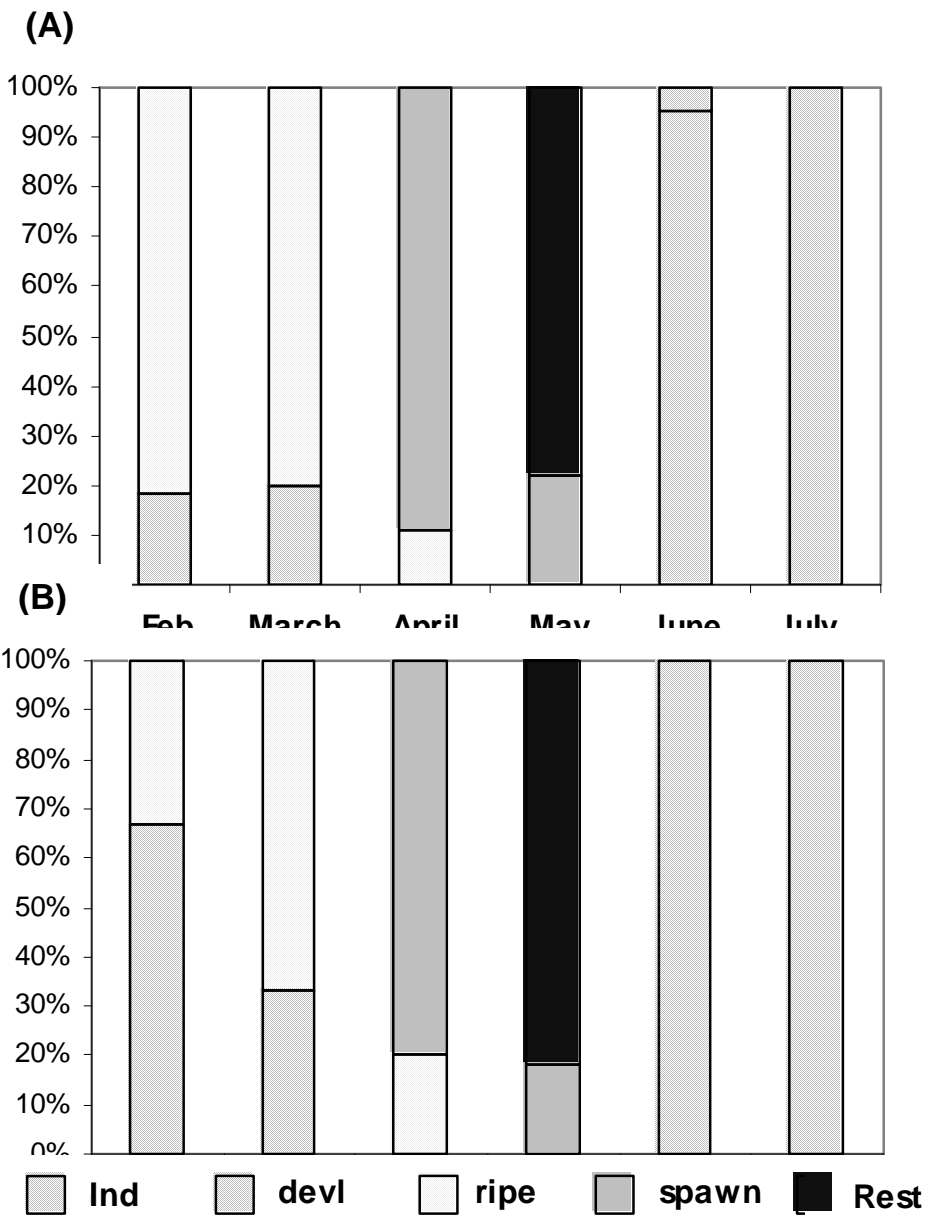

Fig. 1. Monthly percentages for 10 male mussels (A) and 10 female mussels (B) during the different maturation stages from January to July. ind = indifferent stage; dev = development stage; spawn = spawning stage. 


\section{Tables}

\begin{tabular}{|c|c|c|c|c|c|c|}
\hline & \multicolumn{3}{|c|}{ male } & \multicolumn{3}{|c|}{ female } \\
\hline & $\mathrm{Cl}$ & $\begin{array}{c}E 2 \\
\mathrm{ng} \cdot \mathrm{g}^{-1} \mathrm{dw}\end{array}$ & $\begin{array}{c}\% \\
\text { transactivation }\end{array}$ & $\mathrm{Cl}$ & $\begin{array}{c}E 2 \\
n g \cdot g^{-1} d w\end{array}$ & $\begin{array}{c}\% \\
\text { transactivation }\end{array}$ \\
\hline February & $0.16 \pm 0.04^{(a)}$ & $2.39 \pm 0.06$ & $40 \pm 1.2$ & $0.17 \pm 0.03^{(a)}$ & $2.06 \pm 0.3$ & $32 \pm 1.6$ \\
\hline March & $0.13 \pm 0.07^{(b)}$ & $2.05 \pm 0.06$ & $56 \pm 4.5$ & $0.12 \pm 0.02^{(b)}$ & $2.1 \pm 0.21$ & $50 \pm 4$ \\
\hline April & $0.12 \pm 0.04^{(b)}$ & $5.42 \pm 0.16$ & $49 \pm 3.5$ & $0.11 \pm 0.02^{(b)}$ & $5.11 \pm 0.17$ & $56 \pm 1.5$ \\
\hline \multirow[t]{3}{*}{ May } & $0.10 \pm 0.03^{(b)}$ & $4.07 \pm 0.23$ & $65 \pm 5.2$ & $0.12 \pm 0.03^{(b, c)}$ & $4.2 \pm 0.14$ & $51 \pm 2.8$ \\
\hline & & indifferent & & & & \\
\hline & $\mathrm{Cl}$ & $\begin{array}{c}E 2 \\
n g \cdot g^{-1} d w\end{array}$ & $\begin{array}{c}\% \\
\text { transactivation }\end{array}$ & & & \\
\hline June & $0.15 \pm 0.04^{(d)}$ & $4.94 \pm 0.13$ & $56 \pm 1.8$ & & & \\
\hline July & $0.15 \pm 0.03^{(d)}$ & $1.71 \pm 0.06$ & $56 \pm 1.1$ & & & \\
\hline
\end{tabular}

Table 1. $\mathrm{Cl}$, E2 levels and induction of luciferase activity (\% transactivation) in male, female and indifferent mussels from February to July.

$100 \%$ transactivation was obtained with $10 \mathrm{nM} \mathrm{E2}$, basal activity was $20 \%$ of maximal activity. Results of luciferase transactivation per well were obtained for the same dilution of mussel extract. For the male $\mathrm{Cl}$, "a" was significantly different from "b" and "b" from "d". For the female $\mathrm{Cl}$, "a" was significantly different from "b" and "c" from "d". 